\title{
Challenging Sensing Solutions Designed by Sensata Bulgaria
}

A. Tanev, P. Mitsev, T. Lazarova

Key Words: Automotive exhaust gas; platinum temperature sensor; materials technology; automotive pressure sensors.

\begin{abstract}
This paper presents novel green automotive platinum sensing technology together with pressure sensors design principles and applications. In recent years, worldwide emissions legislation has been introduced and is rapidly becoming more stringent. With alternative vehicular propulsion methods far from becoming mainstream reality, leading automotive providers have intensified efforts in the direction of reducing the harmful footprint of their products. This is being accomplished via smaller, appropriately designed internal combustion engines, necessitating an increased and higher-performance sensor content per vehicle. This paper elaborates on temperature sensor application in automotive exhaust gas performance sensing and as well as pressure sensors in different challenging automotive applications with very high pressure levels.
\end{abstract}

\section{Introduction}

The growing environmental awareness within society has necessitated an immediate and effective solution towards air pollution reduction and control [6]. A large portion of the latter is produced every day by the global vehicle fleet, responding to the ever-growing transportation needs of an expanding world population, with automotive being among the three major energy consumer sectors. The above requires a greater degree of sensing, operating under harsher application conditions, prompting the need for novel sensor technology.

\section{Theoretical Background}

In practice, there are three sensor technologies that are viable in vehicle exhaust: thermocouples, thermistors, and resistance temperature detectors (RTD). Each of them has their own advantages and disadvantages, and will be considered in brief detail.

Thermocouples are formed by welding two dissimilar metals together forming a bimetallic junction that produces a temperature-dependent voltage as a result of the thermoelectric effect [17].

For a vehicle application, a type K (chromel-alumel), type R or S (platinum-rhodium) or type N (Nicrosil-Nisil) would be used for the range of temperatures previously mentioned. Thermocouples can be relatively low cost sensors (for example, using type $\mathrm{K}$ ) as compared with thermistors or RTDs. However, the electrical system is significantly more expensive since there must be introduced a compensation for voltages produced whenever there is a change in wire material (often called cold-junction compensation).

Thermocouples can be made with very little mass which allows for a fast response with changing temperature. In order for the sensor to minimize drift and be reliable in a vehicle exhaust environment however, the thermocouple must be protected by a sheath, and therefore they are made thicker. Thus much of the fast response advantage is reduced.

Thermistors are made from various nonmetallic conductors (i.e. metal oxides). The types of thermistors found

Figure 1. Automotive sensors: general view [11] 
in a vehicle exhaust environment will typically produce a negative temperature coefficient (NTC), meaning the resistance will decrease with increasing temperature. Thermistors offer a high sensitivity over a smaller range in temperature than either thermocouples or RTDs [17].

At $0^{\circ} \mathrm{C}$ the resistance can be over $100000 \Omega$, at $200^{\circ} \mathrm{C}$ : 200 to $500 \Omega$, and at $800^{\circ} \mathrm{C} 50 \Omega$. Therefore, thermistors can achieve very high sensitivities over a particular range of temperatures. However, achieving nearly the same accuracy over a large range in temperatures is not possible (unless several pull up resistors are used) due to the highly nonlinear characteristic response. Thermistors can be made with a very small thickness for quick response. However, they are not able to withstand even mild vehicle exhaust environments without being protected by a metal or ceramic insulated sheath thus causing the sensor response to be relatively slow [19].

Tolerance of a thermistor depends on its intended range of use. For example, thermistor tolerances in manifold air temperature sensors (MAT) or coolant sensors are very tight over the relatively narrow range of measurement (ex. $0.6^{\circ} \mathrm{C}$ from $0^{\circ}$ to $100^{\circ} \mathrm{C}$ ). However in a vehicle exhaust that can vary between $-40^{\circ} \mathrm{C}$ and $1000^{\circ} \mathrm{C}$, thermistors have a fairly poor tolerance depending on the temperature range ( $2 \%$ to $6 \%$ of temperature). As previously described, thermistors typically have a very high resistance below $\mathrm{T}=100^{\circ} \mathrm{C}$. This makes it difficult to meet requirements of being able to read the sensor at temperature $-40^{\circ} \mathrm{C}$, or being able to perform OBD (On-Board Diagnostics) start up diagnostics at $20^{\circ} \mathrm{C}$.

Table 1 shows a summarized comparison of the three different sensor types. The RTD is the most accurate of the three sensor types over the entire measurement range over time. It is important to note that zero hour accuracy is only one portion of total accuracy; how the sensor performs in the application over time at temperature is vital [17].

Table 1. Comparison of three sensor technologies

\begin{tabular}{|l|l|l|l|}
\hline Characteristic & Thermocouple & Thermistor & RTD \\
\hline Linearity & Poor & Poor & Good \\
\hline Accuracy & Fair & $\begin{array}{l}\text { Fair to } \\
\text { poor }\end{array}$ & Excellent \\
\hline $\begin{array}{l}\text { Sensitivity } \\
<600^{\circ} \mathrm{C} \\
>600^{\circ} \mathrm{C}\end{array}$ & $\begin{array}{l}\text { Poor } \\
\text { Poor }\end{array}$ & $\begin{array}{l}\text { Excellent } \\
\text { Fair }\end{array}$ & $\begin{array}{l}\text { Good } \\
\text { Good }\end{array}$ \\
\hline $\begin{array}{l}\text { Signal level } \\
<600^{\circ} \mathrm{C} \\
>600^{\circ} \mathrm{C}\end{array}$ & $\begin{array}{l}\text { Poor } \\
\text { Poor }\end{array}$ & $\begin{array}{l}\text { Excellent } \\
\text { Fair }\end{array}$ & $\begin{array}{l}\text { Good } \\
\text { Good }\end{array}$ \\
\hline $\begin{array}{l}\text { Response } \\
\text { time }\end{array}$ & $\begin{array}{l}\text { Poor } \\
(3 \mathrm{~mm} \text { dia })\end{array}$ & Poor & $\begin{array}{l}\text { Good } \\
\text { (No } \\
\text { sheath) }\end{array}$ \\
\hline $\begin{array}{l}\text { System } \\
\text { complexity }\end{array}$ & Poor & Good & Excellent \\
\hline $\begin{array}{l}\text { Standardized } \\
\text { output signal }\end{array}$ & Excellent & Poor & Good \\
\hline $\begin{array}{l}-40^{\circ} \mathrm{C} \\
\text { measurement }\end{array}$ & Excellent & Poor & Excellent \\
\hline $\begin{array}{l}20^{\circ} \mathrm{C} \text { OBD II } \\
\text { measurement }\end{array}$ & Excellent & Poor & Excellent \\
\hline
\end{tabular}

Figure $2[13,14,15,16]$ shows two thermistors and a typical RTD designed for vehicle exhaust use (thermocouples are not shown since they generate an output voltage instead of measuring a resistance). As can be seen from the graph, the thermistors show a very non-linear curve as compared to the RTD. Further, there is a significant difference between the two different thermistor manufacturers, with one not being practical for measuring temperatures below $100^{\circ} \mathrm{C}$. The tolerances indicated on the graph show that the RTD has a much tighter tolerance than thermistors over the measurement range.

Resistance Temperature Detectors (RTDs) operate through the principle of electrical resistance change in metal thermistors. Platinum is the most widely specified RTD element type although nickel, copper, and Balco (nickel-iron) alloys are also used. Platinum is popular due to its wide temperature range, accuracy, stability, as well as the degree of standardization among manufacturers, thus interchangeability. RTDs are characterized by an almost linear positive change in resistance with respect to temperature. They exhibit the most linear signal with respect to temperature of any electronic sensing device [1].

The platinum and copper RTDs are most commonly used [1]. In general, RTDs are employed over the wide temperature range from $260^{\circ} \mathrm{C}$ up to $850^{\circ} \mathrm{C}$, and some of these RTDs are applied up to $1200{ }^{\circ} \mathrm{C}$ [1].

The effect of adding rhodium over the platinum's temperature coefficient of resistance (TCR) is given in figure 4. The quantity of rhodium $(\mathrm{Rh})$ in the Pt-Rh alloy is less than $1 \%$. This is commonly used to control the TCR value. 


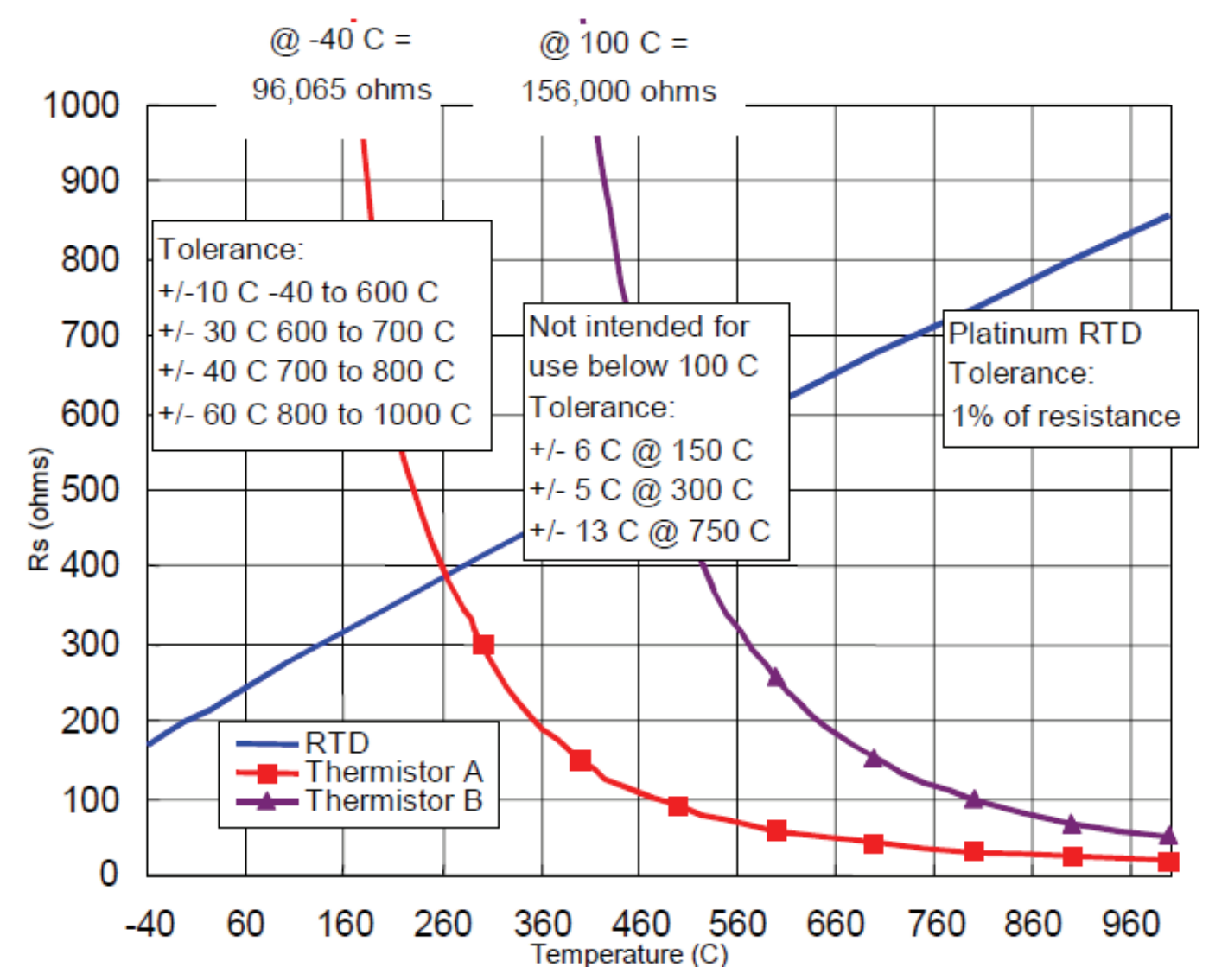

Figure 2. Comparison of three sensors technologies

Pt. Resistivity of alloys. 3.

Electrical resistivity of dilute platinum alloys.

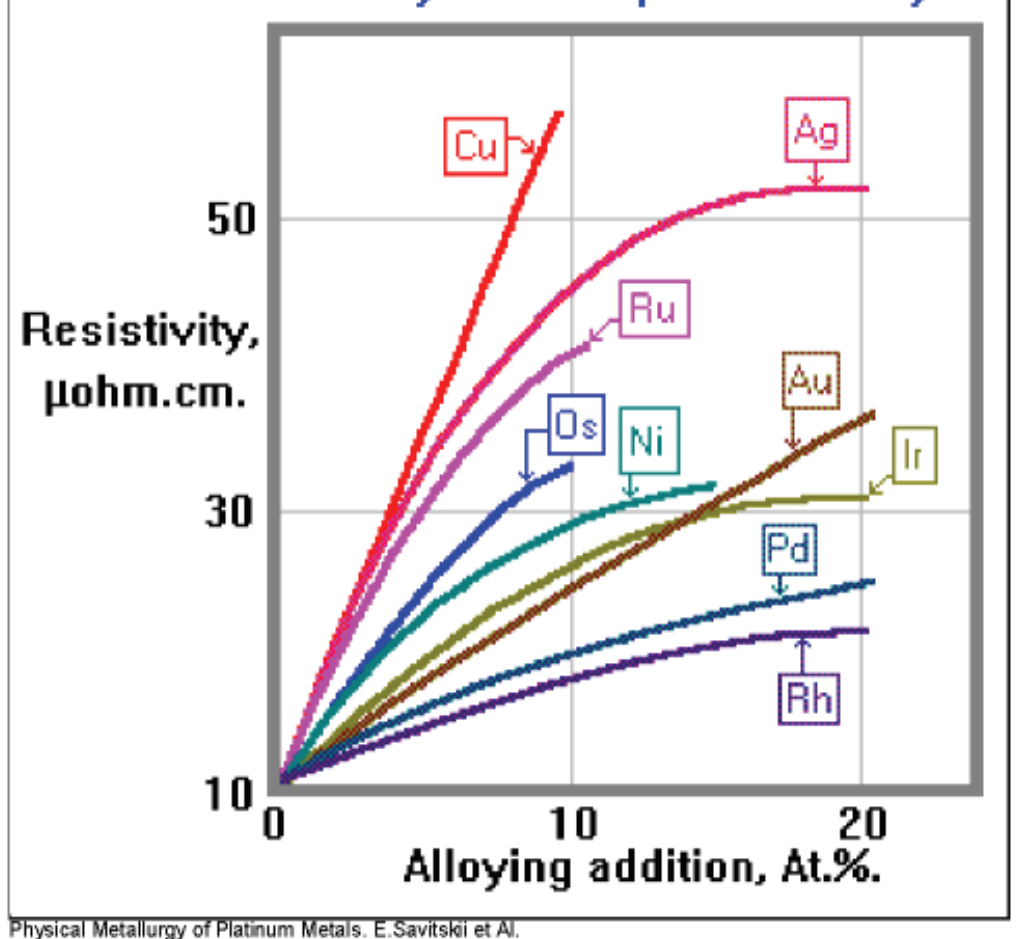

Figure 3. Resistivity of various Pt alloys [6] 


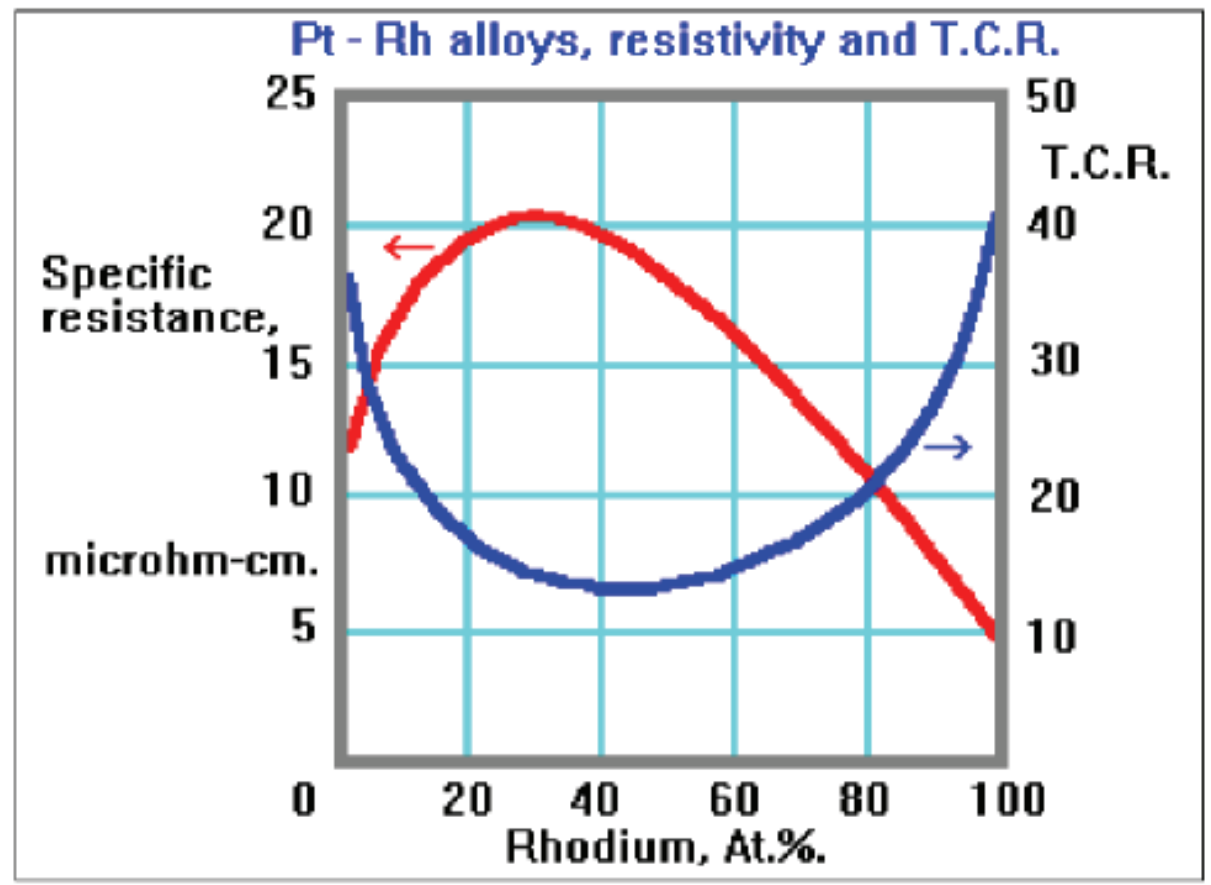

Figure 4. Effect of Rh addition on Pt TCR [12]

The resistance vs. temperature equation is shown below, which is represented by the best-fit quadratic equation of the measured data [2]:

where:

(1) $\mathrm{R}(\mathrm{T})=\mathrm{R}_{0}\left(1+\alpha \mathrm{T}+\beta \mathrm{T}^{2}\right)$

- $\mathrm{R}(\mathrm{T})$ - sensor resistance $[\Omega]$ vs $\operatorname{Temp}\left({ }^{\circ} \mathrm{C}\right)$;

- $\alpha$ is a slope of $\mathrm{R} / \mathrm{R}_{0}$ vs $\mathrm{T}$ line;

- $\beta$ is a non-linear (quadratic) term.

For a standard Pt RTDs, the coefficients $\alpha$ (slope) and $\beta$ (quadratic term) are summarized in table 2.

The standard IEC 751 sets two tolerance classes for
Class B covers the entire range from $-200^{\circ} \mathrm{C}$ to $850^{\circ} \mathrm{C}$.

The Platinum resistance as a function of measured temperature is shown in figure 5. The function is almost linear over a wide range of temperatures (up to $850^{\circ} \mathrm{C}$ ). The resistance at $0^{\circ} \mathrm{C}$ is $\mathrm{R}_{0}=200 \Omega$.

To accomplish the above, design engineering is involved along the scale axis, via different disciplines, shown in figure $6[3,4,5,18]$.

Automotive Pressure Sensors (APT): Sensors \& Controls solid-state pressure transducer is a capacitive-based sensor that provides a linear voltage output directly propor-

Table 2. Pt RTD international standards

\begin{tabular}{|l|l|c|c|}
\hline \multirow{2}{*}{ Standard } & $\begin{array}{c}\text { Temperature } \\
\text { coefficient } \\
\text { of resistance, } \\
\text { (TCR) }\end{array}$ & $\boldsymbol{\alpha}$ & $\boldsymbol{\beta}$ \\
\cline { 2 - 4 } & {$\left[{ }^{\circ}\right]^{-1}$} & {$\left[{ }^{\circ} \mathbf{C}\right]^{-1}$} & {$\left[{ }^{\circ} \mathbf{C}\right]^{-2}$} \\
\hline DIN 43760 & 0.003850 & $3.9080 \mathrm{e}-03$ & $\begin{array}{l}-5.8019 \mathrm{e}- \\
07\end{array}$ \\
\hline American & 0.003911 & $3.9692 \mathrm{e}-03$ & $\begin{array}{l}-5.8495 \mathrm{e}- \\
07\end{array}$ \\
\hline ITS-90 & 0.003926 & $3.9848 \mathrm{e}-03$ & $-5.870 \mathrm{e}-07$ \\
\hline $\begin{array}{l}\text { IEC } \\
60751: 2008\end{array}$ & 0.003851 & $3.9083 \mathrm{e}-03$ & $-5.775 \mathrm{e}-07$ \\
\hline
\end{tabular}

the interchangeability of platinum Pt RTDs [1]:

Class A: Tolerance $\left({ }^{\circ} \mathrm{C}\right)= \pm(0.15+0.002|t|)$

Class B: Tolerance $\left({ }^{\circ} \mathrm{C}\right)= \pm(0.3+0.005|t|)$ where $|t|$ - temperature in ${ }^{\circ} \mathrm{C}$.

Class A applies to temperatures from $-200^{\circ} \mathrm{C}$ to $650^{\circ} \mathrm{C}$, and only for RTDs with three or four-wire configurations. tional to applied pressure. Integral signal conditioning electronics incorporating a custom designed integrated circuit provide an accurate, stable signal over a wide operating temperature range $\left(-40\right.$ to $\left.135^{\circ} \mathrm{C}\right)$. The sensor is compatible with most fluids in pressure-based automotive systems [9].

The principle of operation of an automotive pressure transducer design is provided in figure 7. 
Resistance

$[\Omega]$

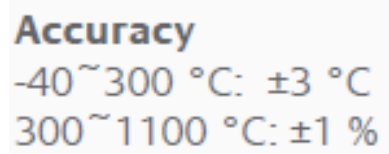

1000

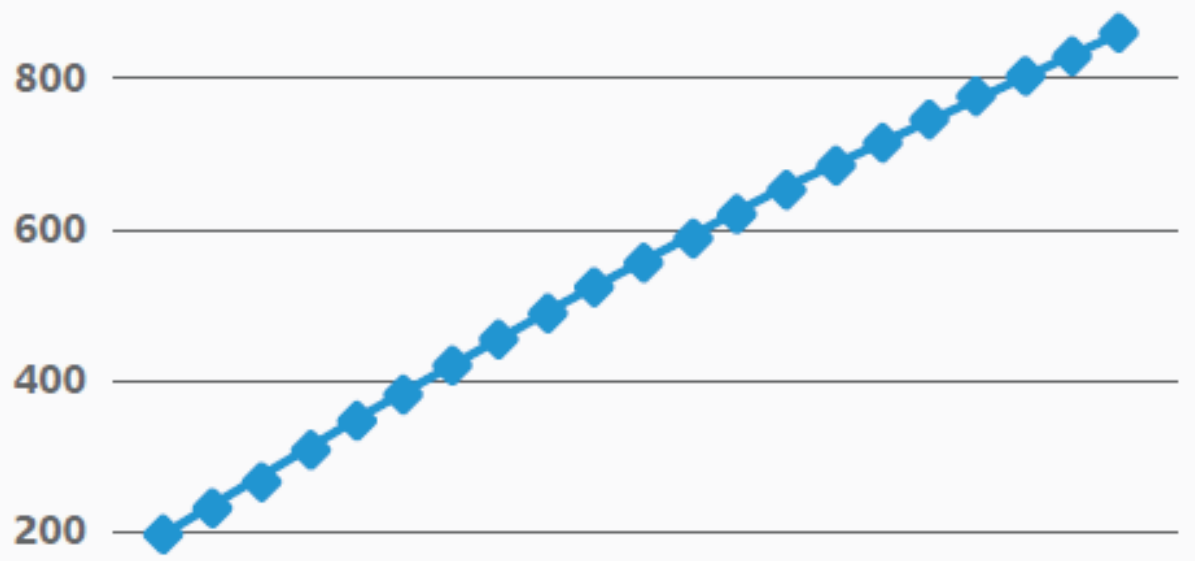

0

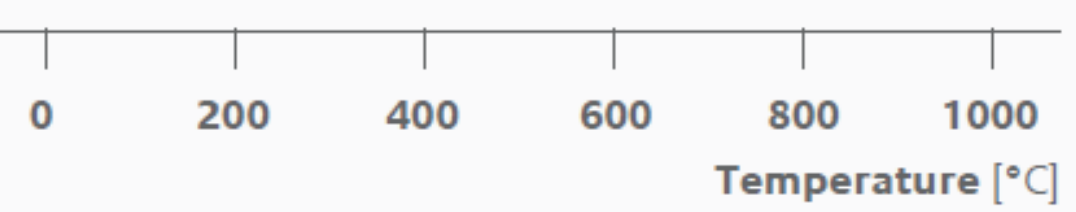

Figure 5. $\mathrm{R}=\mathrm{f}(\mathrm{T})$ function $[7]$

\section{Materials \& Process Simulation capabilities}

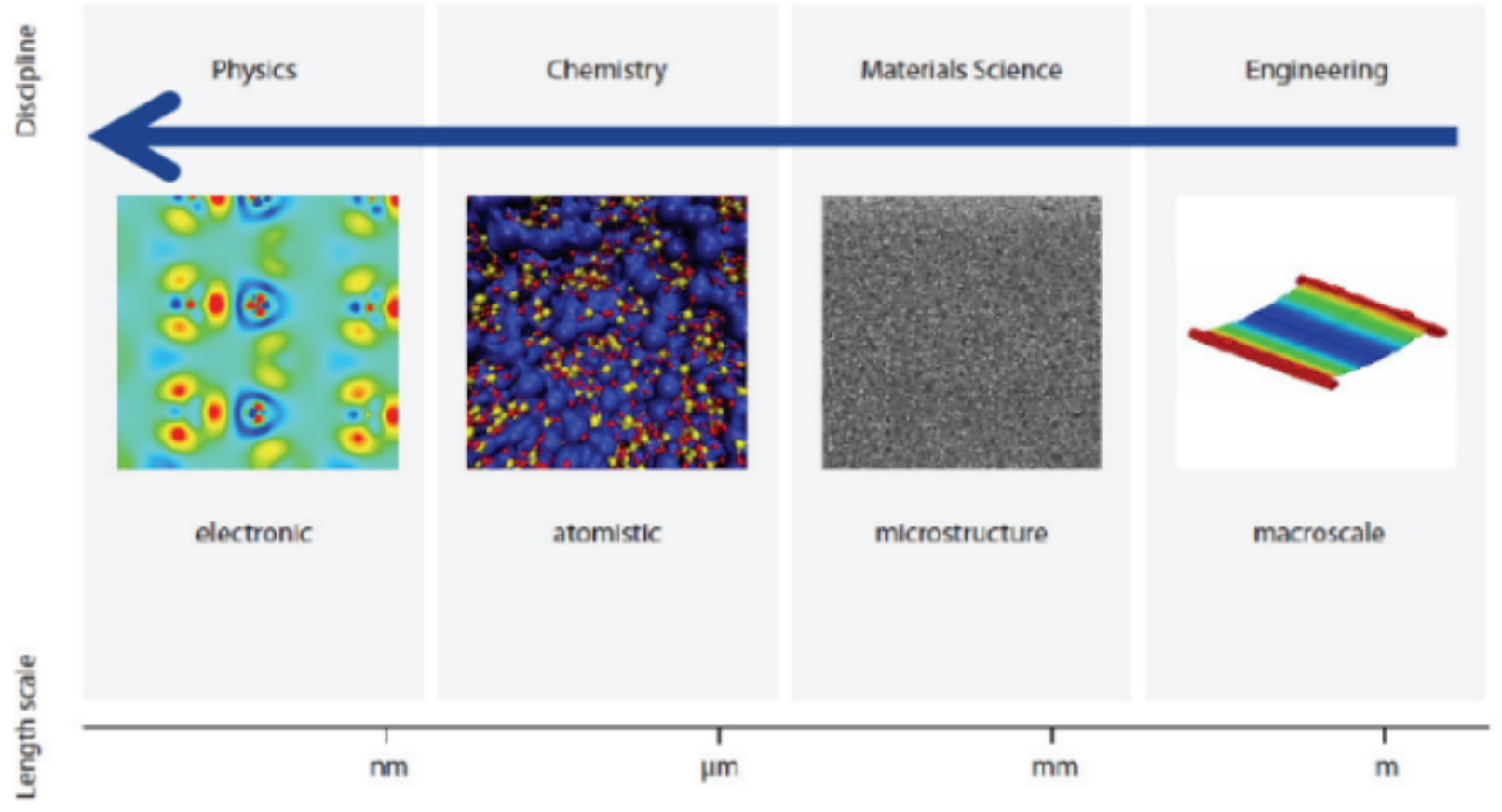

Figure 6. Physical scale versus scientific disciplines, used in sensor design [8] 


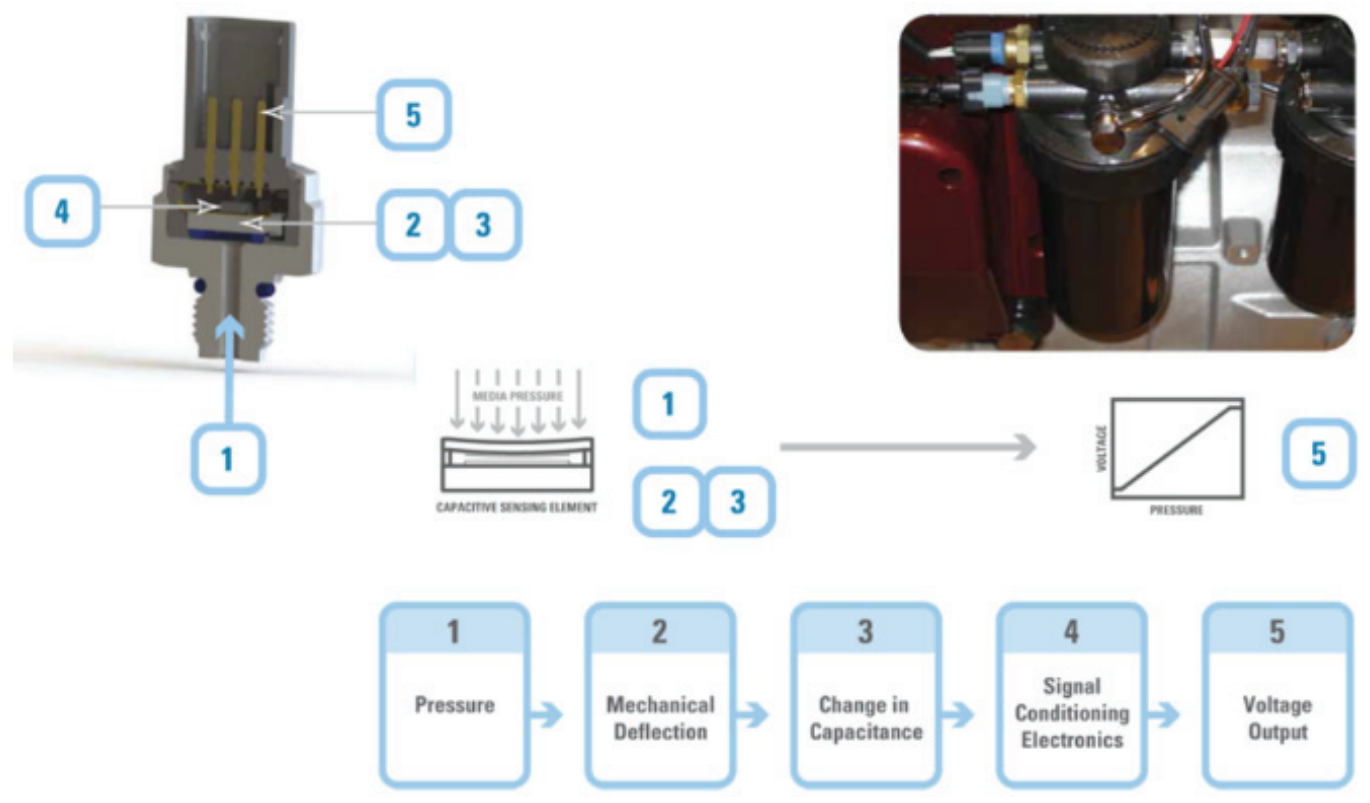

Figure 7. Automotive Pressure sensor (APT): Working Principle

The basics of APT sensors are in the capacitance measurement- Capacitance is the ability of a capacitor to store an electrical charge. A common form - a parallel plate capacitor - the capacitance is calculated by $C=Q / V$, where $C$ is the capacitance related by the stored charge $Q$ at a given voltage $V$. The capacitance (measured in Farads) of a parallel plate capacitor (see figure 7) consists of two conductor plates and is calculated by [18]:

$$
\text { (2) } \mathrm{C}=\frac{\varepsilon_{\mathrm{r}} \varepsilon_{0} \mathrm{~A}}{\mathrm{~d}}
$$

where:

- A is the area of the two plates (in meters);

- $\varepsilon_{\mathrm{r}}$ is the dielectric constant of the material between the plates;

- $\varepsilon_{0}$ is the permittivity of free space $(8.85 \mathrm{e}-12 \mathrm{~F} / \mathrm{m})$.

- $\mathrm{d}$ is the separation between the two plates (in meters).

Automotive Microfused Silicon Strain Gage (MSG): these sensors provide Pressure and Temperature output signals to the application's ECU that is used to control various systems. The output is an analog or digital signal that reflects the pressure and temperature of the medium being measured in the application [10]. The applications of MSG sensors reach up to 3000 Bar pressure levels. The main principle behind the operation of the MSG sensors (see figure 8) is based on the piezoresistive effect of the silicon defined by the expression:

(3) $\frac{\Delta \mathrm{R}}{\mathrm{R}}=\pi \sigma$

where:

- $R$ - resistance $[\Omega]$;

- $\pi$ - piezoresistivity coefficient (typical value may be $1 \mathrm{e}-10 \mathrm{~cm}^{2} /$ dyne);

- $\sigma$ - stress in dyne $/ \mathrm{cm}^{2}$.

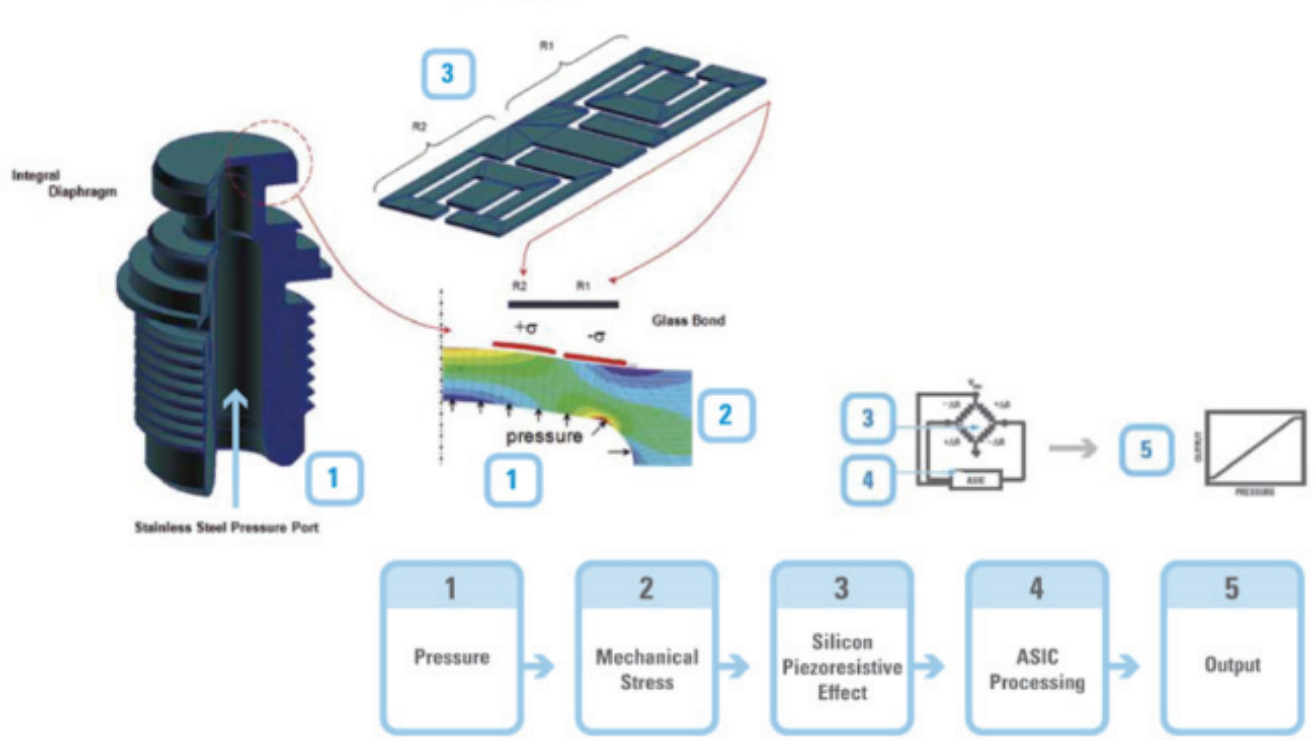

Figure 8. Microfused Silicon Strain Gauge Pressure sensor (MSG): Working Principle 
What is Finite Element Analysis (FEA): it is a numerical method. Traditionally, a branch of Solid Mechanics. Nowadays, a commonly used method for multiphysics problems [20].

What areas can FEA be applied? These are the following:

- Structure analysis: a cantilever, a bridge, an oil platform...

- Solid mechanics: a gear, an automotive power train ...

- Dynamics: vibration of Sears Tower, earthquake, bullet impact...

- Thermal analysis: heat radiation of finned surface, thermal stress brake disc...

- Electrical analysis: piezo actuator, electrical signal propagation...

- Biomaterials: human organs and tissues...

FEA is originally developed for solving solid mechanics problem.

Object: A Solid with known mechanical properties.

\section{Concepts}

- Boundary: The surface enclosing the geometry.

- Solid: Interior + Boundary.

- Boundary conditions: Any prescribed quantities, such as prescribed displacements and prescribed tractions on the boundary.

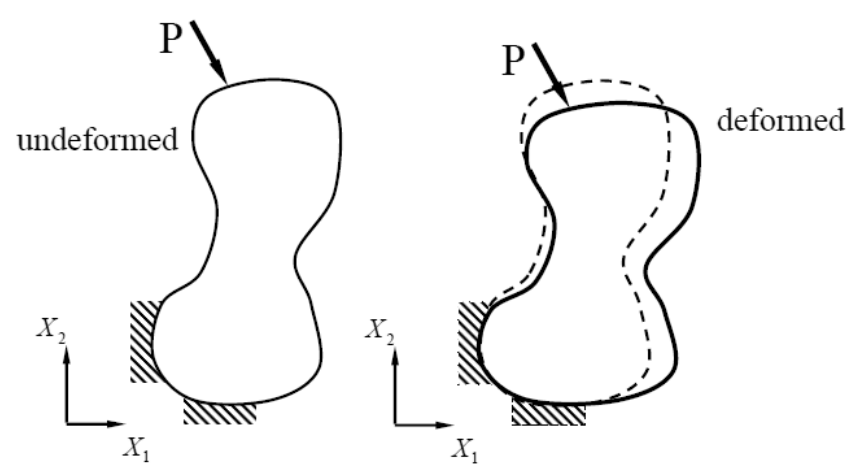

Figure 9. FEA applied to Solid Mechanics

The inputs are boundary conditions (prescribed force; prescribed displacement ...). The output is Stresses, strains, displacements, at each material point $\left(\mathrm{X}_{1}, \mathrm{X}_{2}, \mathrm{X}_{3}\right)$.

Question: If we apply a force on a solid, what are the values of the displacements, stresses, and strains at each material point?

To solve for this problem, we need to refer to the following equations [20]:

(4) $\mathrm{e}_{\mathrm{ij}}=\frac{1}{2}\left[\frac{\partial \mathrm{u}_{\mathrm{i}}}{\partial \mathrm{X}_{\mathrm{j}}}+\frac{\partial \mathrm{u}_{\mathrm{j}}}{\partial \mathrm{X}_{\mathrm{i}}}\right]$;

(5) $\sigma_{\mathrm{ij}}=2 \mathrm{Ge}_{\mathrm{ij}}+\lambda \mathrm{e}_{\mathrm{kk}} \delta_{\mathrm{ij}}$;

(6) $\frac{\partial \sigma_{i 1}}{\partial X_{1}}+\frac{\partial \sigma_{i 2}}{\partial X_{2}}+\frac{\partial \sigma_{i 3}}{\partial X_{3}}+f_{i}=0$.

We need to solve a problem consisting of total 15 equations, among which nine equations are partial differential equations! Finding an exact solution is impossible. Then the mission changes to find a solution which approximates the exact solution. Therefore, FEA is a numerical method that offers a means to find this approximate solution [24].

How does FEA works? Let's consider one example an integration using numerical methods

(7) $F=\int_{-1}^{1}\left(x^{2}+6\right) d x$.

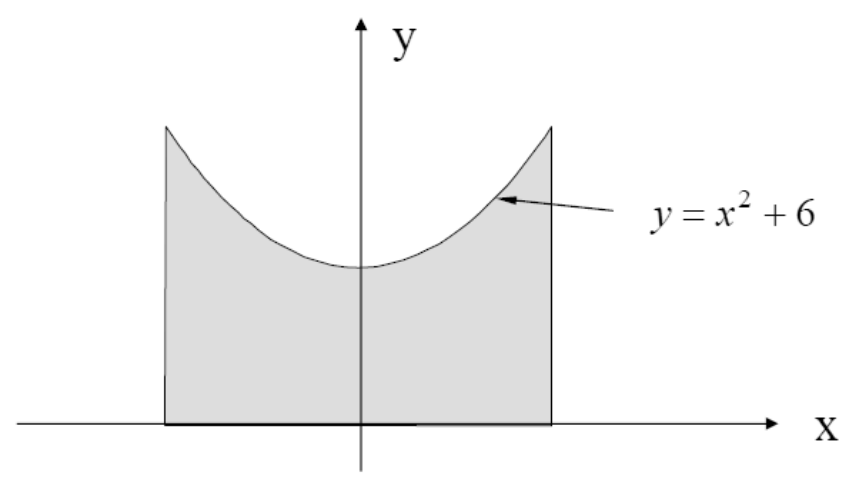

Figure 10. The integration represents the area under the curve

The exact solution of Eq. (7) is

(8) $\mathrm{F}=\int_{-1}^{1}\left(\mathrm{x}^{2}+6\right) \mathrm{dx}=\left.\left(\frac{\mathrm{x}^{3}}{3}+6 \mathrm{x}\right)\right|_{-1} ^{1}=\approx 12.667$.

\section{Numerical Integration - Scheme 1}

1. Divide the interval of integration into $\mathrm{N}$ section.

2. Choose a function to approximate the variation of $\mathrm{f}(\mathrm{x})$ in each section; the simplest such function is a constant function that equals to the value of $f(x)$ at the midpoint of each section.

3. The product of this constant function and the length of the section approximates the integration of $\mathrm{f}(\mathrm{x})$ over this section.

4. Summing the products for all sections gives an approximate answer to the integration of $f(x)$ over the interval $(-1,1)$.

The error in the numerical integration in case of $\mathrm{N}=1$ is $-5.26 \%$ (figure 11 ) and $-1.32 \%$ with $\mathrm{N}=2$ (figure 12 ).

The error is reduced significantly in cases with $\mathrm{N}=4$ and $\mathrm{N}=8$. Therefore, as the number of sections increases, the error decreases.

\section{Numerical Integration - Scheme 2}

Same as Scheme 1, except that we choose a linear function in each section to approximate the variation of $\mathrm{f}(\mathrm{x})$. This linear function takes the same value and slope of $f(x)$ at the mid-point of that section.

Two key steps have to be considered:

1. Divide the interval of integration.

2. In each sub-interval, choose proper simple functions to approximate the true function. 


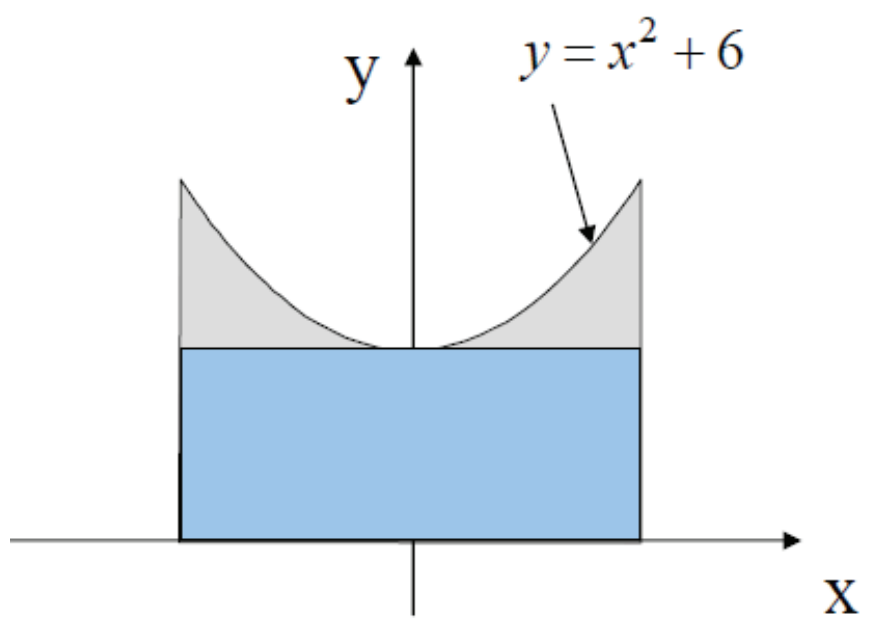

$\mathrm{N}=1, \mathrm{~F}=12$, Error $=-5.26 \%$

Figure 11. The numerical integration error with $\mathrm{N}=1$

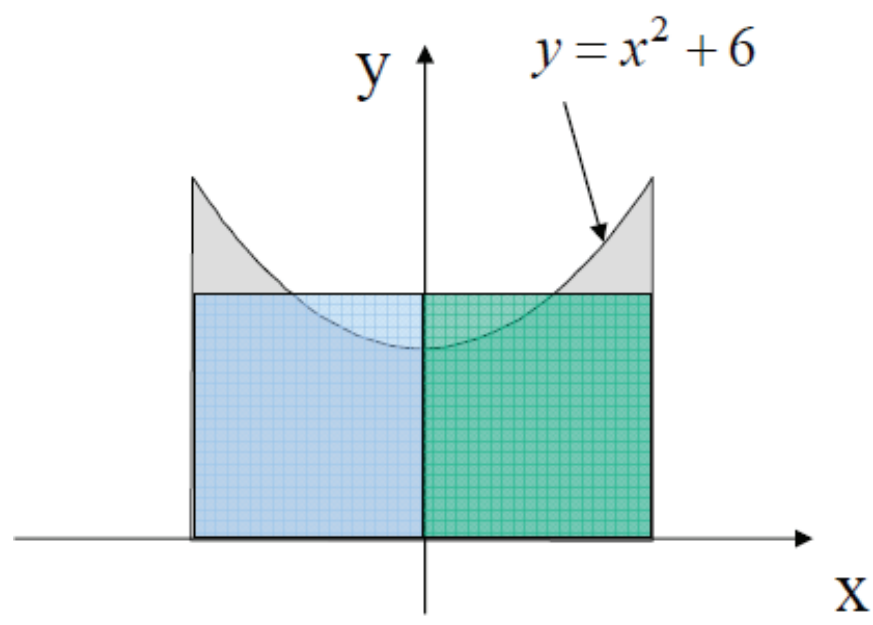

$\mathrm{N}=2, \mathrm{~F}=12.5$, Error $=-1.32 \%$

Figure 12. The numerical integration error with $\mathrm{N}=2$

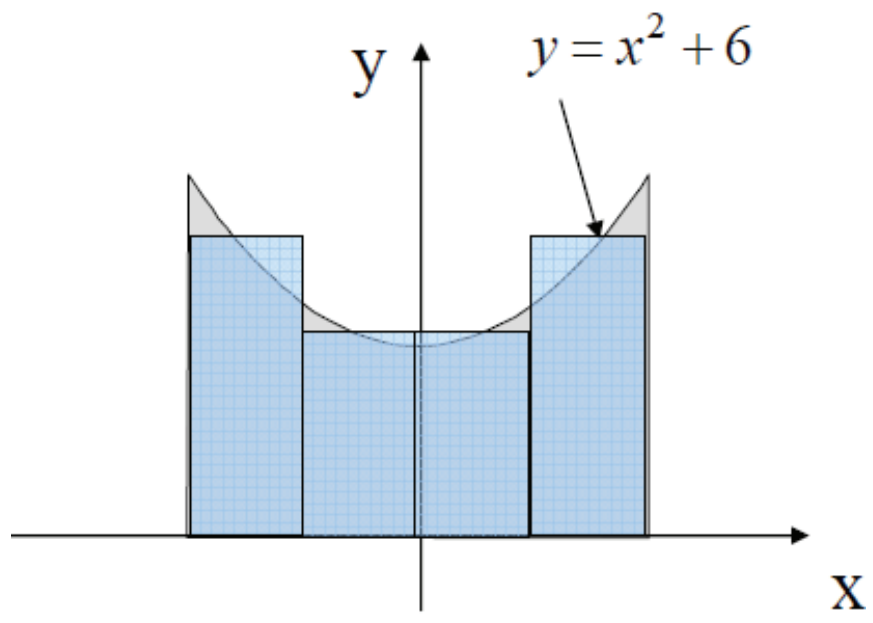

$\mathrm{N}=4, \mathrm{~F}=12.625$, Error $=-0.33 \%$

Figure 13. The numerical integration error with $\mathrm{N}=4$

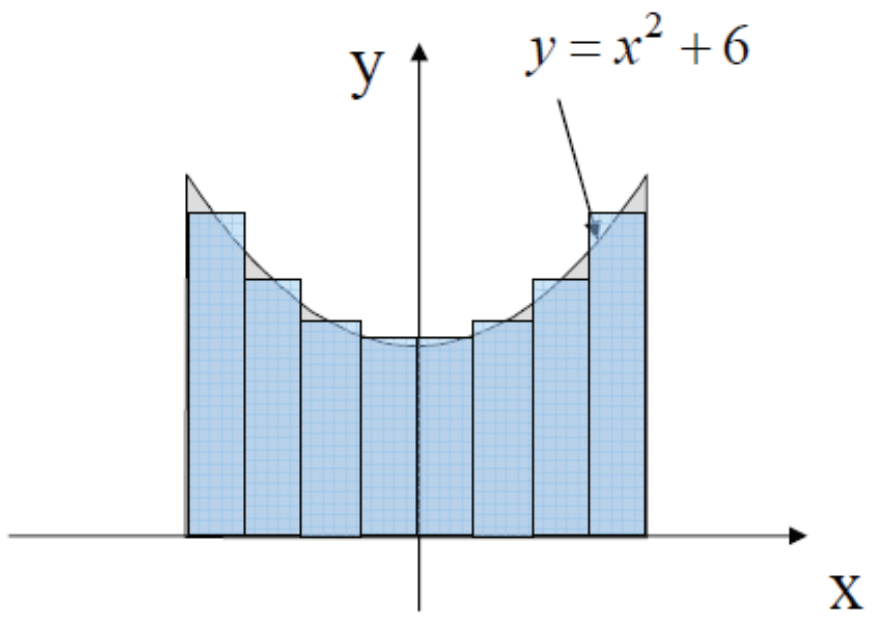

$$
\mathrm{N}=8, \mathrm{~F}=12.656, \text { Error }=-0.08 \%
$$

Figure 14. The numerical integration error with $\mathrm{N}=8$

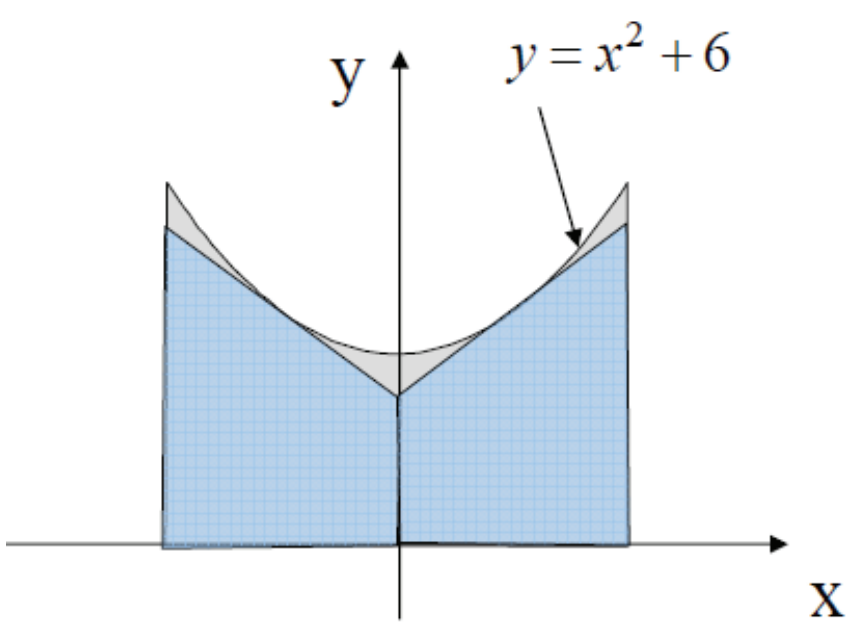

Figure 15. Choice of different function to approximate $f(x)$

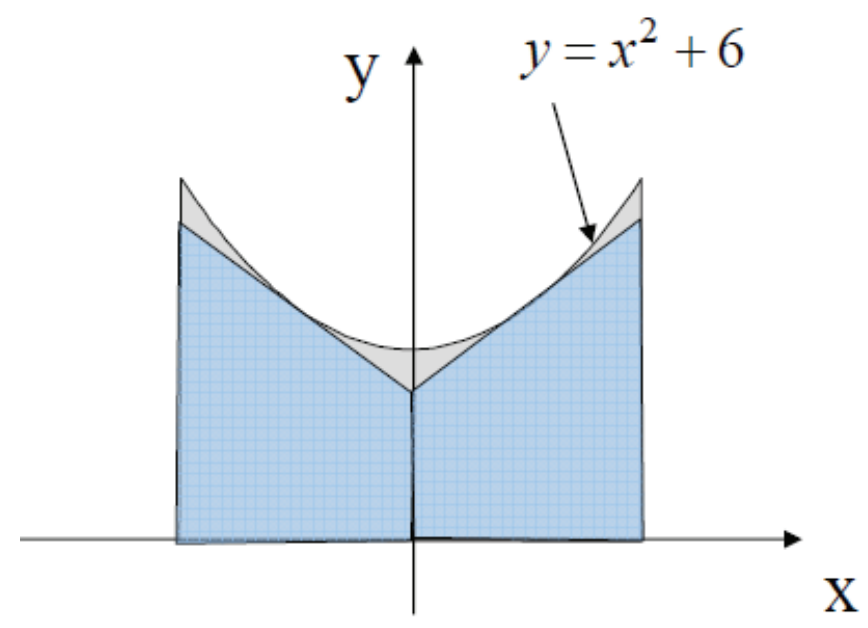

Figure 16. Choice of different function to approximate $f(x)$ 
Two key features:

1. The numerical result is an approximation to exact solution.

2. The accuracy of numerical result depends on the number of sub-interval and approximate function.
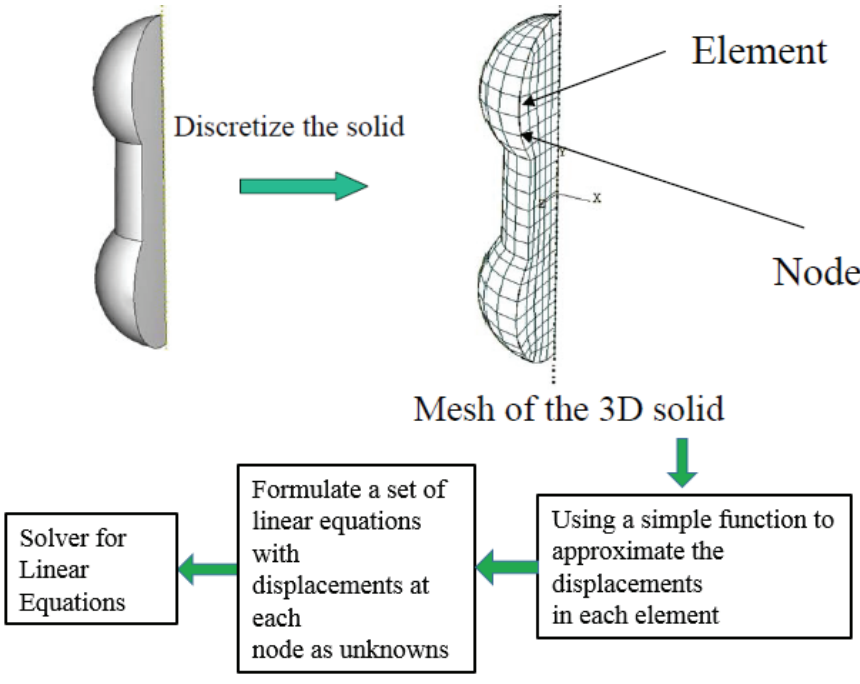

Figure 17. Key steps in FEA work

The general procedure for FEA is shown in figure 18.

\begin{tabular}{|l|l|}
\begin{tabular}{|l|l|}
\multicolumn{1}{|c|}{ Physical Model: } \\
$\begin{array}{l}\text { Describe the problem: } \\
\text { Simplifying a real engineering } \\
\text { problem into a problem that } \\
\text { can be solved by FEA }\end{array}$
\end{tabular} \\
\begin{tabular}{|l|l|}
\hline \multicolumn{1}{|c|}{$\begin{array}{l}\text { FEA Model: } \\
\text { Results: } \\
\text { Obtain, visualize and } \\
\text { explain the results and } \\
\text { make conclusions }\end{array}$} & $\begin{array}{l}\text { FEA Theory: } \\
\text { define material properties, } \\
\text { apply boundary conditions }\end{array}$ \\
\hline
\end{tabular} \\
\hline
\end{tabular}

Figure 18. General procedure of FEA analysis

Example: FEA analysis done on a Platinum $(\mathrm{Pt})$ sensor for high temperature applications. The picture in figure 19 shows the results from the simulation: Equivalent stress (von Mises). The FEA analysis has studied the surrounding components and their influence over the stress in the platinum layer.

To measure the true value of a process variable it is essential that the sensors chosen fit the application and provide very accurate and stable calibration for steadystate measurements and fast dynamic response for transient measurements. A second requirement is the appropriate process-to-sensor interface. For example, fluid temperatures in industrial plants are typically measured with sensors that are installed in thermowells secured to the process piping. The thermowell serves as the process-to-sensor interface and must be designed and installed in the process with the correct insertion depth, exact dimensional tolerances, and proper support to protect the temperature sensor, allow for its easy insertion and removal, and optimize dynamic response. At first glance, these provisions would seem to be easy to accommodate, and frequently they are. However, even a slight deviation can significantly affect critical process measurements, especially when temperatures, pressures, and flow rates are high. For example, tolerance issues involving the length or diameter of sensors or thermowells can cause temperature data to lag far behind the true process temperature, causing control issues and safety concerns [23].

The process-to-sensor interface for pressure transmitters (including liquid level and fluid flow sensors) are the sensing lines that connect the transmitter to the process. Fluid sensing lines are typically made of small-diameter tubing or piping consisting of root, isolation, and check valves; condensation pots; and other components. All these components must function properly to yield accurate and timely data to the plant control and safety systems. Naturally, operational stresses, aging, and installation issues can cause anomalies in sensing lines and contribute to measurement errors as well as dynamic response problems [23].

The dynamic response of a sensor or a system may

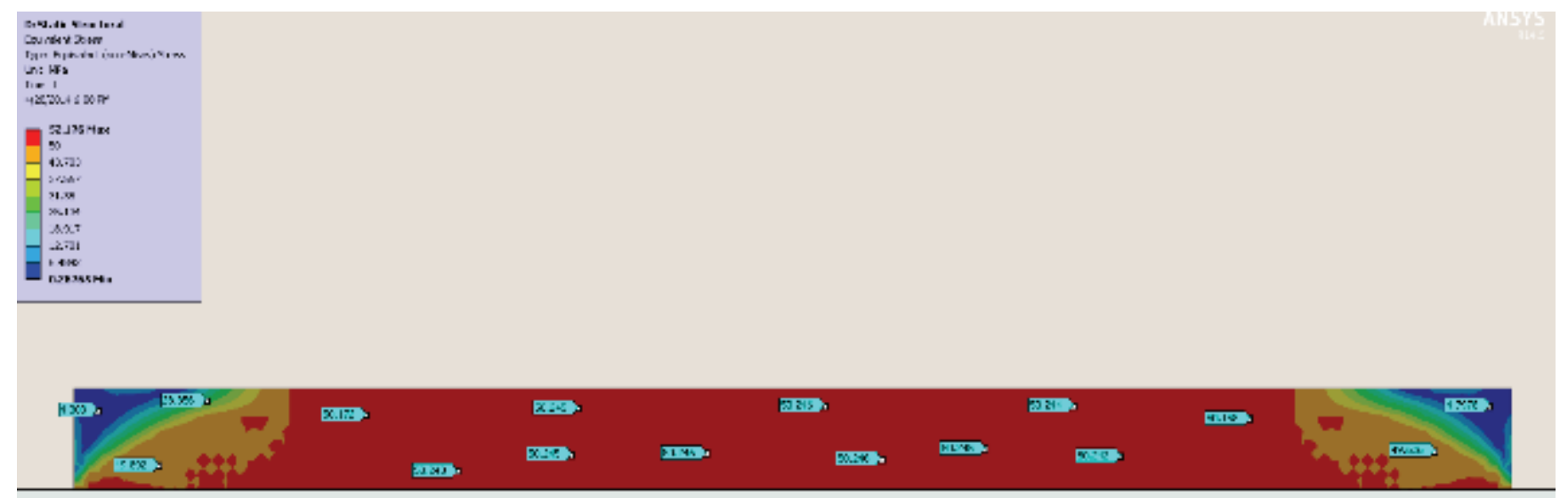

Figure 19. Results from FEA simulations 


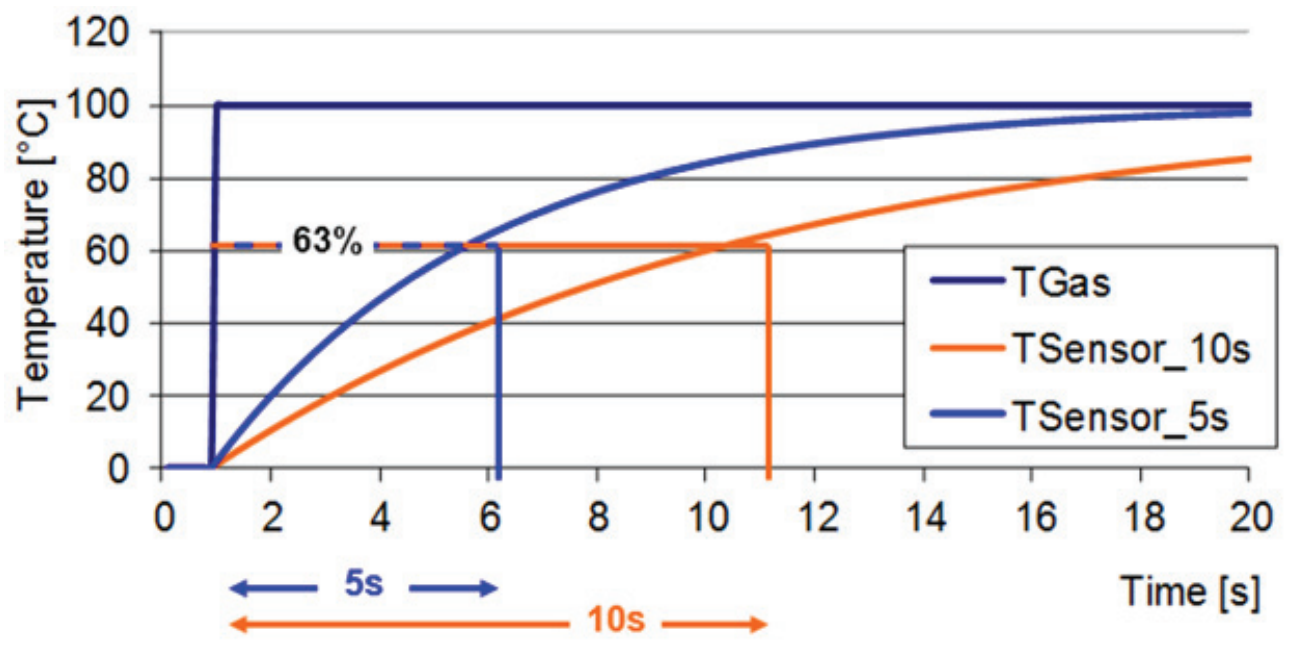

Figure 20. Step response of a first-order thermal system

be identified theoretically or experimentally. The theoretical approach usually requires a thorough knowledge of the design of the sensor, its construction details, the properties and geometries of the sensor's internal material as well as a knowledge of the properties of the medium surrounding the sensor. Since these properties are not known thoroughly, or may change under process operating or aging conditions, the theoretical approach alone can only provide approximate results. A remedy is to combine the theory with experiments that empirically determine the dynamic response [21].

Theory is used to determine the expected behavior of the sensor in terms of an equation called the "model", which relates the input and the output of the system. The system is then given an experimental input signal, and its output is measured and matched with the model. That is, the coefficients of the model are changed iteratively until the model matches the data within a predetermined convergence criterion. This process, performed on a digital computer, is referred to as "fitting". Once the fitting process is successfully completed, the coefficients of the model are identified and used to determine the response time of the sensor. However, if the sensor can be represented with a first-order model, fitting is not necessary because the response time can be determined directly from the output of the sensor [21].

The step response of a first-order thermal system [22] is shown in figure 20.
The response of a sensor can be described by the following model [22]:

where:

(9) $\vartheta_{(\mathrm{t})}=\vartheta_{\mathrm{s}}\left(1-\exp \left(-\frac{\mathrm{t}}{\tau}\right)\right)$

- $\vartheta$ is the temperature $\left[{ }^{\circ} \mathrm{C}\right]$;

- $\vartheta_{\mathrm{s}}$ is the temperature step;

- $\mathrm{t}$ is time [s];

- $\tau$ is time-constant [s].

The time-constant $\tau$,i.e. the value at which the sensor output reaches $63 \%$ from the steady-state level can be expressed by the following equations [22]:

$$
\text { (10) } \begin{aligned}
\tau & =\frac{\mathrm{C}_{\vartheta} \mathrm{b}}{\alpha \mathrm{A}} \\
\tau & =\frac{\mathrm{cmb}}{\alpha \mathrm{A}}
\end{aligned}
$$

where:

- $\mathrm{C}_{\vartheta}$ is heat capacity;

- $\mathrm{c}$ is specific heat capacity;

- $\mathrm{b}$ is thickness of the layer;

- $\mathrm{m}$ is thermal mass;

- $\alpha$ is thermal transfer coefficient;

- A is surface.

The factors influencing the sensor's step response are summarized in table 3.

The model for a sensor or a system may be expressed

\begin{tabular}{|c|c|c|c|c|c|c|}
\hline No & Parameter & $\begin{array}{l}\text { Aluminum } \\
\text { Nitride }\end{array}$ & $\begin{array}{l}\text { Boron } \\
\text { Nitride }\end{array}$ & $\begin{array}{l}\text { Diamond } \\
\text { powder }\end{array}$ & $\begin{array}{l}\text { Alumina } \\
\left(\mathrm{Al}_{2} \mathrm{O}_{3}\right) \\
99.5 \%\end{array}$ & $\begin{array}{l}\text { Magnesium } \\
\text { Oxide }\end{array}$ \\
\hline 1. & Specific Heat, $c_{p}\left[\mathrm{cal} / \mathrm{g}-^{\circ} \mathrm{C}\right.$ ] & 0.25 & 0.19 & 0.10 & 0.21 & 0.19 \\
\hline 2. & Thermal conductivity [W/mK] & $82.3-170$ & $20-60(28)$ & 2.7 & $82.3-170$ & $30-60$ \\
\hline 3. & Electrical Resistivity [ $\Omega \mathrm{cm}]$ & $>10^{14}$ & $10^{13}$ & $>10^{4}$ & $>10^{14}$ & $10^{13}$ \\
\hline 4. & $\begin{array}{l}\text { Coefficient of Linear Thermal } \\
\text { Expansion, al }\left[\mu \mathrm{m} / \mathrm{m}-{ }^{\circ} \mathrm{C}\right] \\
\left(\sim 25^{\circ} \mathrm{C} \text { through } \pm 1000^{\circ} \mathrm{C}\right)\end{array}$ & $4.6-5.7$ & $1.0-2.0$ & 11.0 & 8.4 & $1.0-2.0$ \\
\hline 5. & Thermal Shock Resistance $\Delta \mathrm{T}\left[{ }^{\circ} \mathrm{C}\right]$ & 400 & $>1500$ & $280-360$ & 200 & $>1500$ \\
\hline 6. & Maximum Use Temperature $\left[{ }^{\circ} \mathrm{C}\right]$ & 1600 & $985-1200$ & 500 & 1750 & 985 \\
\hline
\end{tabular}

Table 3. Typical step-response-related properties of established insulating materials [22] 
in terms of either a time domain or a frequency domain equation.

- The time domain model is usually a specific relationship that gives the transient output of the system for a given input signal such as a step or a ramp signal.

- The frequency domain model is often represented as a general relationship called the "transfer function", which includes the input and the output. If the transfer function is known, the system response can be obtained for any input. As such, the transfer function is often used in analyzing system dynamics.

\section{Applications}

The technology, described in this paper, is used to satisfy the world's growing need for safety, energy efficiency and a clean environment. Incorporation examples are provided below [9]. Due to the increased atutomotive systems introduction together with their complexity, sensor content per vehicle is increasing (figure 21).

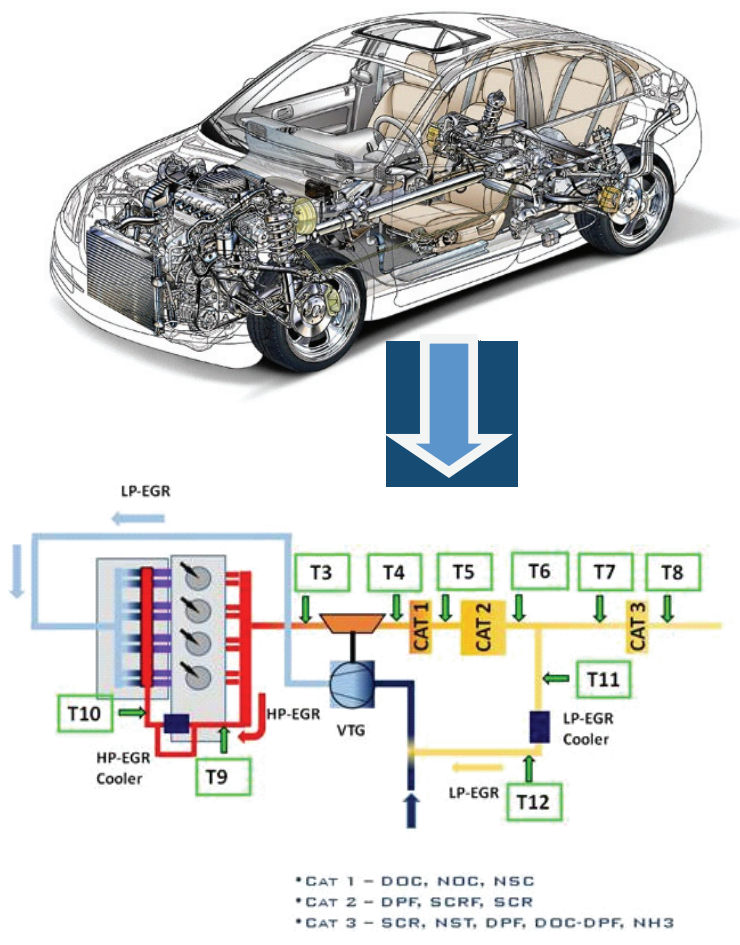

Figure 21. Temperature sensor positions along the exhaust tract $[10]$

Typically, several exhaust gas temperature sensors are positioned along the thermodynamic chain (figure 21). For example, diesel trucks- starting with the 2007 model year- used for on highway applications are required to have an exhaust treatment system to reduce emissions, specifically large particulate matter. The diesel particulate filter (DPF) is a component of the system. DPFs are designed to physically filter particulate matter (soot). A regeneration process removes the accumulated soot from the filter.

The Automotive Pressure sensors (APT):
APsquared $^{\mathrm{TM}}$ Automotive Sensor [10] are with the features shown in table 4 and applications (see figure 22).

Table 4. APT sensor features and benefits

\begin{tabular}{|l|l|}
\hline Features & Benefits \\
\hline \multirow{2}{*}{ Square sense element } & Lower costs \\
\cline { 2 - 2 } & Lighter weight \\
\hline Flexible packaging & Available in a wide range of connectors and port fittings \\
\cline { 2 - 2 } & Ease of system integration \\
\hline High reliability in noisy environments & EMC protection to $200 \mathrm{~V} / \mathrm{m}$ \\
\hline Balanced circuit design & \\
\hline Generation II or III conditioning & Accuracy $\pm 1 \%$ Vcc \\
\cline { 2 - 2 } electronics & Temperature compensation \\
\hline Ratiometric output & Ease of system integration \\
\cline { 2 - 2 } & Eliminates error in supply voltage fluctuations \\
\hline $\begin{array}{l}\text { Designed for under-hood } \\
\text { environments }\end{array}$ & $\begin{array}{l}\text { Operating temperature range of }-40^{\circ} \mathrm{C} \text { to } 135^{\circ} \mathrm{C} \text {; fluid } \\
\text { compatibility }\end{array}$ \\
\hline
\end{tabular}

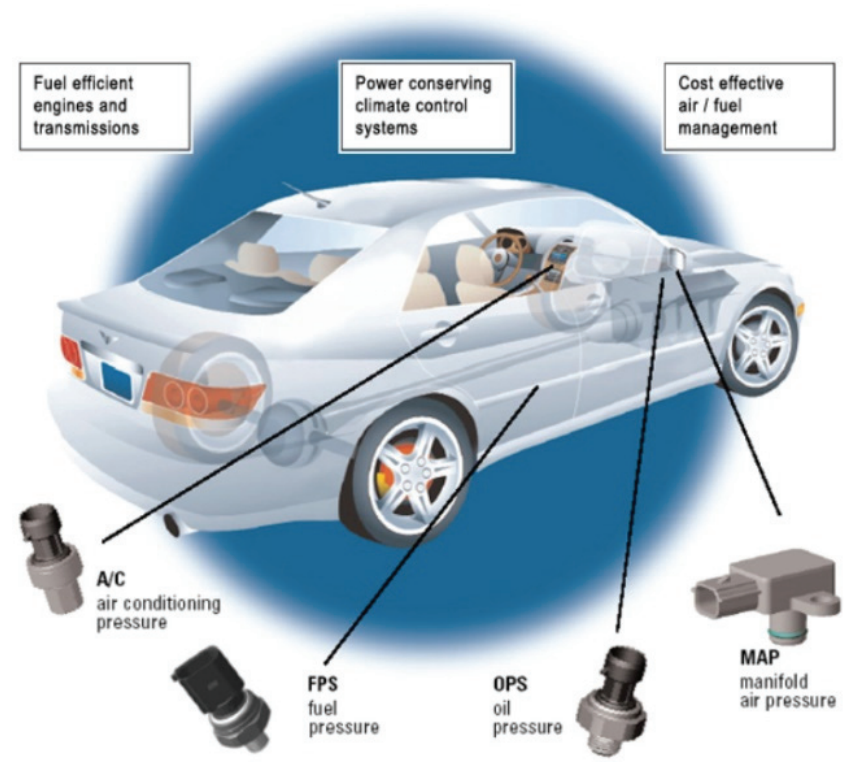

Figure 22. APT pressure sensor positions applications

MSG sensors application (figure 23): Gasoline Direct Injection (GDI) and Common Rail Pressure Sensors: Accurate fuel rail Pressure Sensing Is Crucial for Fuel System Management, Fuel economy, emissions and OBDII [11].

\section{Conclusion}

In this paper, the application of automotive exhaust gas temperature sensing, along the length of the thermodynamic tract, and pressure sensors have been described. The influence of metal alloy composites on resistivity and the temperature coefficient of resistivity, thus sensor signal, has been elaborated. The physical scale to scientific discipline design implications has been discussed, providing for performance sensors of increased stability and reliability. The strength of Finite Element Analysis (FEA) has been highlighted with a described theoretical background and 


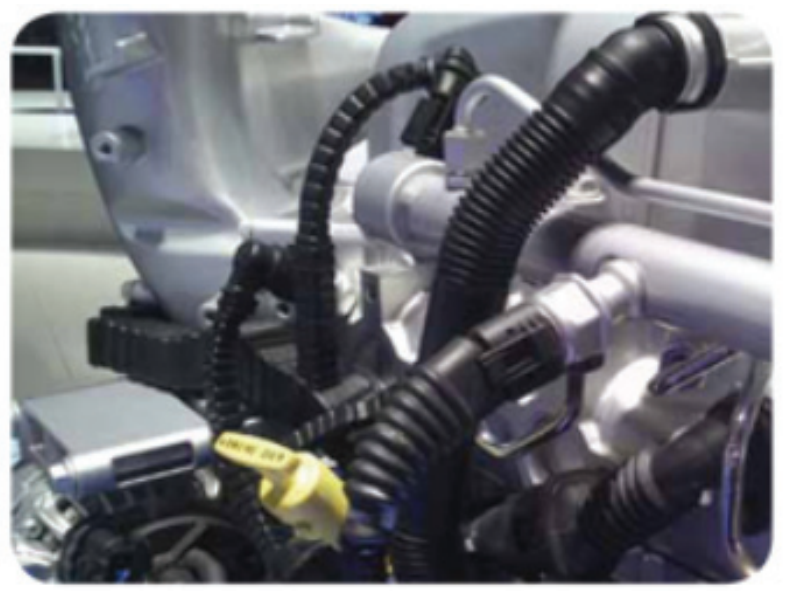

Figure 23. MSG pressure sensor positions/applications

application to Platinum $(\mathrm{Pt})$ sensor in high temperature applications.

The pressure sensors MSG provide robust port design, hermetic electronics cavity capability and high accuracy with low weight and small size. Their typical applications are Gasoline Direct Injection (GDI) and Common Rail.

The APT sensors provide compact design that allows for local pressure sensing, they are adaptable up to 5000 PSI (pounds per square inch), absolute or relative sensing. Their typical applications are anti-lock braking/vehicle stability control, transmission, suspension, power steering, etc.

\section{References}

1. Adler, B. Reliability Aspects of Temperature Measurement. Moore Industries-International, Inc., North Hills, CA 91343.

2. http://www.ni.com/tutorial/7115/en/.

3. Fischer et al. Practical Experience with New Oxide Dispersion

\section{Manuscript received on 01.11.2016}

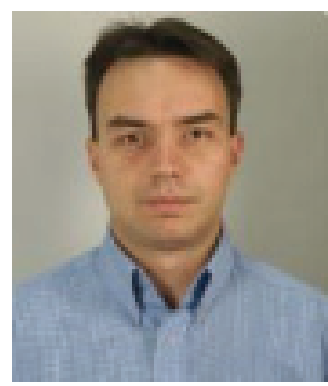

Angel Tanev is a Dr-Ing. in Reliability engineering (2009) and MSc in Automation and System engineering (2002). His experience in Automotive domain is since 2006: design and development of Ana$\log$ and Digital Clusters; Body Controllers; Clocks; Displays; High Temperature and Pressure Sensors. He is currently working in sensors design engineering and exploring the scientific field of reliability and safety. His research interests include also stochastic systems, risk analysis, forecasting and operations research.

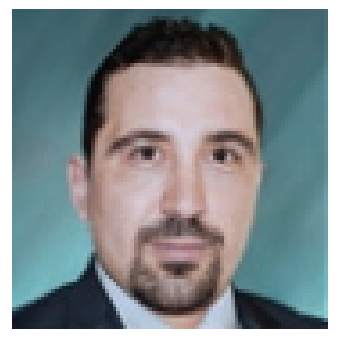

Peter Mitsev joined Sensata in 2007 and is an Industrial Designer, passionate about high impact delivery through established and avant grade technical and leadership skills + resource management. Specialties include team inspiration and development, materials/layer technology, concept inception, analysis, supplier synergy, Six Sigma, CI.
Hardened Platinum Materials. Tucson, Arizona, USA, 9-12 June 2001. 4. Josй S. Moya, Sonia Lopez-Esteban, Carlos Pecharromøn. The Challenge of Ceramic/Metal Microcomposites and Nanocomposites. - Progress in Materials Science, 52, 2007, 1017-1090.

5. Ke Fan, Min Liu, Tianyou Peng, Liang Maa, Ke Dai. Effects of Paste Components on the Properties of Screen-printed Porous TiO2 Film for Dye-sensitized Solar Cells. - Renewable Energy, 35, 2010, 555-561.

6. Savitski, E. et al. Physical Metallurgy of Platinum Metals. 1978.

7. Kyocera Pt 200 RTD Product Datasheet.

8. Materials Design MedeA Product Presentation.

9. Sensata Technologies Inc.

10. Sensata Technologies Inc.

11. Sensata Technologies Inc.

12. The PGM Database. www.pgmdatabase.com.

13. Desmarais, R. et al. How to Select and Use the Right Temperature Sensor. Sensors Magazine, 2001.

14. LeGare, J. et al. Temperature Sensors for On-board Diagnosis of LEV/ULEV Systems. Automotive Engineering, 1995.

15. Mathews, D. Choosing and Using a Temperature Sensor. Sensors Magazine, 2000.

16. Volbrecht, A. Temperature Measurement: Making Sense of It All. Sensors Magazine, 1998.

17. Nelson, C., et al. The Development of a RTD Temperature Sensor for Exhaust Applications. Delphi Corporation, SAE International, 2004.

18. http://www.ti.com/lit/an/snoa927/snoa927.pdf.

19. Gindev, E. Introduction in the Theory and the Practice of Reliability. Part 2. Basics of the Practical Reliability. Sofia, Academic Publishers "Prof. Marin Drinov", 2000.

20. http://www.colorado.edu/MCEN/MCEN4173/lecture notes.html. 21. Kerlin, T. W. Frequency Response Testing in Nuclear Reactors. New York, Academic Press, 1974.

22. Public Domain+STB.

23. Hashemian, Hashem M. Measurement of Dynamic Temperatures and Pressures in Nuclear Power Plants. Electronic Thesis and Dissertation Repository. Paper 189, 2011.

24. Petrov, N. I. Reliability's Investigations of Risk Technical Systems. Yambol, Bulgaria, Publishing House "Jelio Uchkov", 2007.

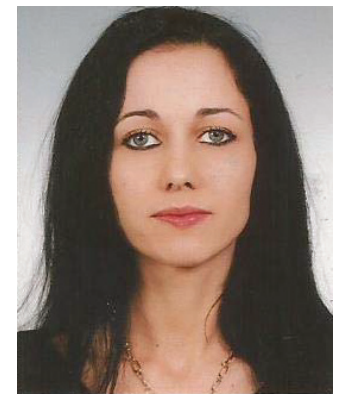

Tsvetelina Lazarova is design engineer working in a major international company with very strong global reputation. I enjoy being challenged and working on projects that require me to work outside my comfort and knowledge set, as continuing to learn and develop my knowledge at different aspects is important to me. Furthermore, I am multi-task oriented, enjoy a challenge, and continually stay abreast of the latest advancements of technologies. I work hard and remain effective under pressure. I have consistently achieved all deadlines set and take care to ensure that I plan ahead and priorities of my workload.

Interests: Microstructural Characterization of Materials, Properties, Selection and Testing of Materials; New product development from concept idea, through development, all the way to manufacturing; Structured problem solving.

Contacts: Sensata Technologies Bulgaria Trade Center Europe, Building 1 7 Iskarsko Shose Blvd., 1578 Sofia, Bulgaria e-mails:a-tanev@sensata.com pmm@sensata.com tlazarova@sensata.com 